\title{
ON THE IMPACT OF SNOW COVER ON DAYTIME POLLUTION DISPERSION
}

\author{
M. Segal,* J. R. Garratt, † R. A. Pielke, † P. Hildebrand,§ F. A. Rogers, \\ J. CRamer $\ddagger$ and A. Schanot§ \\ *Department of Physics and Astronomy, The University of Kansas, Lawrence, KS 66045, U.S.A., †CSIRO \\ Division of Atmospheric Research, Private Bag No. 1, Mordialloc, Victoria, 3195, Australia, łDepartment \\ of Atmospheric Science, Colorado State University, Fort Collins, CO 80523, U.S.A., §National Center for \\ Atmospheric Research, P.O. Box 3000, Boulder, CO 80307, U.S.A. and \| Mobil Research and Development \\ Corporation, Paulsboro Research Lab., P.O. Box 480, Paulsboro, NJ 08066-0480, U.S.A.
}

(First received 10 September 1989 and in final form 5 November 1990)

\begin{abstract}
A preliminary evaluation of the impact of snow cover on daytime pollutant dispersion conditions is made by using conceptual, scaling, and observational analyses. For uniform snow cover and synoptically unperturbed sunny conditions, observations indicate a considerable suppression of the surface sensible heat flux, the turbulence, and the development of the daytime atmospheric boundary layer (ABL) when compared to snow-free conditions. However, under conditions of non-uniform snow cover, as in urban areas, or associated with vegetated areas or bare ground patches, a milder effect on pollutant dispersion conditions would be expected. Observed concentrations of atmospheric particles within the ABL, and surface pollutant concentrations in urban areas, reflect the impact of snow cover on the modification of ABL characteristics.
\end{abstract}

Key word index: Snow cover, boundary layer, turbulence over snow, urban pollution.

\section{INTRODUCTION}

Snow-covered ground, in extensive populated industrialized regions, is known to be a common feature in many geographical locations at particular times of the year. In northern mid-latitude locations, snow cover may persist throughout most of the winter, while in southern mid-latitude locations snow cover occurs occasionally. As will be evaluated in the present study, snow-covered ground should cause, on many occasions, significant modifications of the daytime atmospheric boundary layer (ABL) thermal and turbulence characteristics when compared to the ABL above snow-free ground. These modifications are primarily attributed to changes in the surface sensible heat fluxes. Since the ABL thermal characteristics are a major factor affecting pollutant dispersion, the related pollutant dispersion characteristics should also be modified. The impact of snow cover on the atmospheric surface layer is documented to some degree in the literature, and it is considered in hydrological and some weather forecasting aspects (e.g. Dewey, 1977; Gray and Male, 1981; Bluestein, 1982). However, according to the accessible research literature no attempt has been made to evaluate the impact of snow cover on mid-latitude pollutant dispersion. The present study makes a preliminary attempt in this direction.

The evaluations provided in the present study (appropriate for clear sky situations), are based on conceptual and scaling considerations and observations. As such they provide an initial general view on the problem, rather than a specific case study evaluation.
The significance of the surface sensible heat flux is emphasized, since the ABL turbulence characteristics and depth are strongly correlated to this flux. Estimates of the modifications in the surface sensible heat flux induced by a uniform snow cover (compared with snow-free, vegetated surfaces) are given in section 2. A general evaluation of the impact on the surface sensible heat flux when snow surfaces are non-uniform, as in urban areas, is given in section 3 . Evaluation of the potential impact of snow cover on near-surface dispersion, and estimation of the possible range of the $\mathrm{ABL}$ depth over snow in relation to pollutant trapping, both in terms of their dependence on surface sensible heat flux into the atmosphere, are provided in section 4. Various illustrative meteorological observations of the ABL characteristics over snow cover compared to those over snow-free surfaces, are given in section 5 . Observational evaluations of the impact of snow cover on pollution concentrations are given in section 6 .

\section{EVALUATION OF THE SURFACE SENSIBLE HEAT FLUXES OVER UNIFORM SNOW COVER}

The major impact of snow cover (as compared to snow-free ground) on pollutant dispersion characteristics is primarily related to a significant suppression of the daytime supply of surface sensible heat flux, $H_{\mathrm{s}}$, into the atmosphere, or even a reversal in the direction of the heat flux. Modifications of $H_{s}$ have an impact on dispersion-related characteristics: the turbulence intensity in the lower atmosphere, and consequently the depth of the ABL. In the following, two approaches for 
the estimation of $H_{\mathrm{s}}$ over uniform snow cover are adopted. The first is a scaling approach related to energy partitioning, and the second is based on the typical range of surface wind speed and thermal stratification over snow cover. The problem of estimating $H_{\mathrm{s}}$ under non-uniform snow-cover situations, as in the urban environment, is discussed in section 3 .

\subsection{Formulation of $\mathrm{H}_{s}$ based on energy considerations}

The major causes for the suppression of $H_{\mathrm{s}}$ over snow-covered surfaces are listed below.

(1) The snow temperature is $\leqslant 273 \mathrm{~K}$. On sunny and relatively warm days (i.e. with an air temperature $>273 \mathrm{~K}$ ), surface temperatures of snow-covered areas are lower than temperatures of bare ground surfaces under the same atmospheric conditions.

(2) The amount of short wave solar radiation is reduced at the surface due to an increase in surface albedo over a snow surface. Snow albedo may reach values as high as 0.95 in the visible region of the spectrum, although reflection reduces substantially in the near i.r. region, i.e. above $>0.7 \mu \mathrm{m}$ (e.g. Mellor, 1977; Wiscombe and Warren, 1980). It should be noted that the albedo over a snow surface tends to increase somewhat with an increase in the sun zenith angle (i.e. during the morning and the afternoon hours). In addition, the potential penetration into the snow layer of solar radiation reaching the snow surface contributes to a reduction in the net available solar radiation at the surface.

(3) The relatively low surface roughness over uniform snow results in a reduced value of $H_{\mathrm{s}}$.

Taking (1)-(3) together suggests, in most cases, a major reduction in the surface sensible heat flux, and thus of turbulence, compared to snow-free ground under the same environmental conditions. In the following, the various forcings which govern $H_{\mathrm{s}}$ are analyzed. From these evaluations one can infer related impacts on the thermal stability of the surface layer.

Using the concept of the Penman-Monteith combination equation (Penman, 1956; Monteith, 1981), the surface sensible heat from a saturated surface can be approximated [see e.g. Segal et al. (1989) and references therein] as:

$$
H_{\mathrm{s}}=\Gamma\left(R_{\mathrm{LN}}+\eta R_{\mathrm{S}_{\mathrm{o}}}-k_{\mathrm{s}}\left(\frac{\partial T_{\mathrm{sn}}}{\partial z}\right)_{z=0}\right)-\Gamma \rho_{\mathrm{a}} L_{\mathrm{s}} \delta q_{\mathrm{a}} r_{\mathrm{a}}^{-1},
$$

where, following Monteith (1981):

$$
\begin{aligned}
s & =\frac{\partial q^{*}}{\partial T} \approx \frac{q^{*}\left(T_{\mathrm{s}}\right)-q^{*}\left(T_{\mathrm{a}}\right)}{T_{\mathrm{s}}-T_{\mathrm{a}}}, \\
\Gamma & =\frac{\gamma}{s+\gamma} .
\end{aligned}
$$

In Equation ( $2 a), q^{*}$ is the saturated specific humidity (the asterisk superscript indicates a saturated value), $T$ is the temperature, $T_{\mathrm{s}}$ is the snow surface temperature, $T_{\mathrm{sn}}$ is the snow temperature, and $T_{\mathrm{a}}$ is the temperature at a reference level in the air. The sign convention in Equation (1) is that non-radiative fluxes are positive away from the surface and radiative fluxes are positive towards the surface.

The following notation is adopted in Equation (1):

$R_{\mathrm{S}_{\mathrm{o}}} \quad$ the global solar radiation at the snow surface $\left(R_{\mathrm{S}_{\mathrm{o}}}=(1-a) R_{\mathrm{S}}\right.$, where $a$ is the snow albedo and $R_{\mathrm{S}}$ is the global solar radiation reaching the snow surface)

$R_{\mathrm{LN}} \quad$ the net long wave radiation at the snow surface

$L_{\mathrm{s}} \quad$ the latent heat of sublimation

$\delta q_{\mathrm{a}} \quad$ the air specific humidity deficit/surplus near the surface, and is a function of temperature, $T_{\mathrm{s}}$

$r_{\mathrm{a}}$ the aerodynamic resistance for heat or moisture transfer near the surface

$\gamma=\left(\frac{C_{\mathrm{p}}}{L_{\mathrm{s}}}\right)$ the psychrometric constant $\left(C_{\mathrm{p}}\right.$ is the specific $k_{\mathrm{s}} \quad$ the snow thermal conductivity

$\eta \quad$ solar radiation absorption efficiency at the surface

$\rho_{\mathrm{a}} \quad$ air density.

The values of $\Gamma$, dependent on the surface temperature, $T_{s}$, are given in Table 1 indicating a typical range of $0.59-0.9$.

\begin{tabular}{|c|c|c|c|c|c|c|c|c|c|c|c|c|c|}
\hline \multirow[b]{2}{*}{$\Gamma$} & \multirow[b]{2}{*}{$\begin{array}{c}T_{\mathrm{s}} \\
(\mathbf{K})\end{array}$} & \multicolumn{2}{|c|}{0.3} & \multicolumn{2}{|c|}{0.4} & \multicolumn{2}{|c|}{0.5} & \multicolumn{2}{|c|}{0.6} & \multicolumn{2}{|c|}{0.7} & \multicolumn{2}{|c|}{0.8} \\
\hline & & 350 & (140) & 300 & (120) & 250 & $(100)$ & $\begin{array}{l}200 \\
s_{0}\end{array}$ & (80) & 150 & $(60)$ & 100 & (40) \\
\hline 0.90 & 248 & 315 & (126) & 270 & (108) & 220 & (90) & 180 & (72) & 135 & (54) & 90 & (36) \\
\hline 0.85 & 253 & 298 & (119) & 255 & (102) & 213 & (85) & 170 & (69) & 128 & (51) & 85 & (34) \\
\hline 0.79 & 258 & 276 & (111) & 237 & (95) & 198 & (79) & 158 & (63) & 119 & (47) & 79 & (32) \\
\hline 0.71 & 263 & 249 & (99) & 213 & (85) & 178 & (71) & 142 & (57) & 107 & (43) & 71 & (28) \\
\hline 0.62 & 268 & 217 & (87) & 186 & (74) & 155 & (62) & 124 & (50) & 93 & (37) & 62 & (25) \\
\hline 0.59 & $273_{\mathrm{H}_{2} \mathrm{O}}$ & 207 & (83) & 177 & (71) & 148 & (59) & 118 & (47) & 89 & (35) & 59 & (24) \\
\hline
\end{tabular}

Table 1. Values of $\Gamma$ and $\Gamma R_{\mathrm{S}_{0}}\left(\mathrm{~W} \mathrm{~m}^{-2}\right)$ for various combinations of snow surface temperature, $T_{s}$, and snow albedo, $a$, values. Computations are given for incident global solar radiation, $R_{\mathrm{s}}$, of $500 \mathrm{~W} \mathrm{~m}^{-2}$ and $200 \mathrm{~W} \mathrm{~m}^{-2}$ (in parentheses) 
Table 2. Values of the energy $\Gamma\left(R_{\mathrm{S}_{0}}+R_{\mathrm{LN}}\right)$ for various combinations of $T_{\mathrm{s}}$ and $a$ values. The values of $\Gamma R_{\mathrm{S}_{0}}$ are those computed in Table 1 [for $R_{\mathrm{S}}=500 \mathrm{~W} \mathrm{~m}^{-2}$ and $200 \mathrm{Wm}^{-2}$ (in parentheses)]

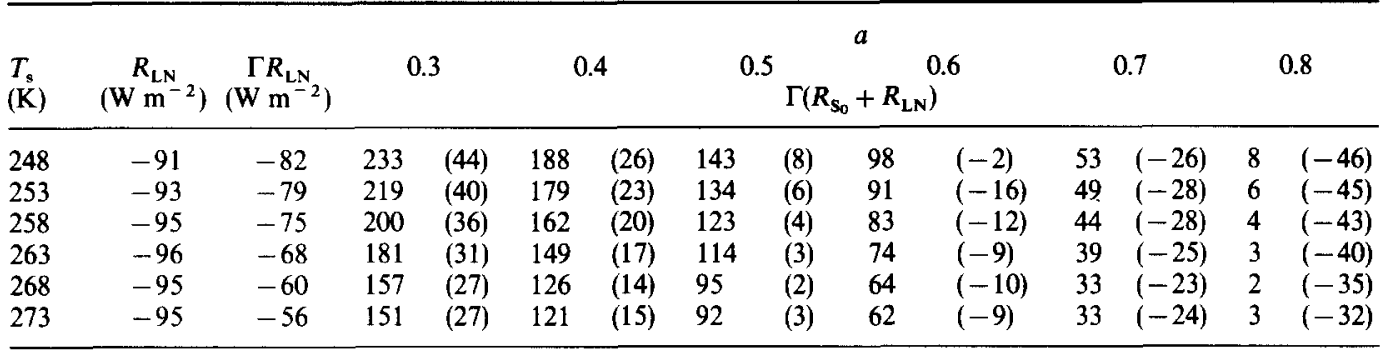

The value of the net long wave radiation, $R_{\mathrm{LN}}$, is approximated using Swinbank's (1963) relation:

$$
R_{\mathrm{LN}} \cong-\sigma T_{\mathrm{s}}^{4}\left(1-9.37 \times 10^{-6} T_{\mathrm{s}}^{2}\right) .
$$

Values of $R_{\mathrm{LN}}$ for various temperatures computed from Equation (3) are given in Table 2. Their magnitudes are comparable with observed $R_{\mathrm{LN}}$ values (e.g. Aguado, 1985), though somewhat lower than that obtained using Brunt's empirical relation [see e.g. Haltiner and Martin (1957), p. 130].

The first term on the r.h.s. of Equation (1) represents a so-called "energy term" contribution to the surface sensible heat flux, while the second term on the r.h.s. involves an "aerodynamic" contribution to the surface sensible heat flux.

In the energy term, $\eta(<1)$ is a parameter indicating the efficiency of the contribution of the global solar radiation, $\boldsymbol{R}_{\mathrm{S}_{0}}$, to the surface sensible heat flux through absorption at the opaque snow surface (i.e. for impure snow $\eta \rightarrow 1$, as for bare soil). On the other hand, for fresh snow, $\eta \rightarrow 0$ because the solar radiation penetrates into the snow layer with its extinction due to absorption given by $R_{\mathrm{S}}(z)=R_{\mathrm{S}_{\mathrm{o}}} z^{-\alpha_{\lambda} z}$. Here $z$ is the depth below the snow surface, $\alpha_{\lambda}$ is the extinction coefficient within the snow for a given wavelength, $\lambda$, and $R_{\mathbf{S}}(z)$ is the solar radiation flux at depth $z$. The values of $\alpha_{\lambda}$ in the near i.r. $(>0.7 \mu \mathrm{m})$ are larger than those for short wave radiation, so that most of the near i.r. is absorbed in the top snow layer. However, well established empirical relations for $\alpha_{\lambda}$ are apparently undocumented, mostly due to large variability in the snow physical properties which affect $\alpha_{\lambda}$. When $\eta \rightarrow 0$ (i.e. there is no direct contribution of $\boldsymbol{R}_{\mathbf{S}_{\mathrm{o}}}$ to the energy term in Equation (1)), the absorbed solar radiation in the snow layer contributes indirectly to the surface energy through the thermal conduction (i.e. solar radiation absorbed within the snow contributes to an increase in snow temperature below the surface and, as a result, to an increase in the conduction term $\left.-\left.k_{\mathrm{s}}\left(\partial T_{\mathrm{sn}} / \partial z\right)\right|_{z=0}\right)$. This contribution, however, is obviously constrained by $k_{\mathrm{s}}\left(\partial T_{\mathrm{sn}} / \partial z\right)<R_{\mathrm{s}_{0}}$. [For the impact of the penetration of solar radiation on the thermal stratification of the snow layer see, for example, Geiger (1965), p. 211.]

When the snow layer is very shallow a relatively large fraction of $R_{\mathrm{S}_{\mathrm{o}}}$ may reach the soil surface result- ing in soil heating. On many occasions, the snow temperature is $273 \mathrm{~K}$ (as on sunny warm days) and according to observations, the upper snow layer is nearly uniform in temperature at $273 \mathrm{~K}$, with $k_{\mathrm{s}}\left(\partial T_{\mathrm{sn}} / \partial z\right)$ tending to be relatively small; most of the solar energy absorbed by the snow is consumed by melting.

Table 1 provides values of $\eta \Gamma R_{\mathrm{S}_{0}}$, with $\eta=1$ for various values of albedo, $a$, and for incident global solar radiation fluxes, $R_{\mathrm{S}}$, of $500 \mathrm{~W} \mathrm{~m}^{-2}$ (e.g. midlatitude noon global solar radiation) and $200 \mathrm{~W} \mathrm{~m}^{-2}$ (e.g. morning hour global solar radiation). These values provide an upper limit for potential global solar radiation contributions to the energy term in Equation (1). As outlined previously, under fresh snow conditions, only a fraction (and occasionally, a very small fraction) of the potential contribution of the global solar radiation is converted into surface thermal snow fluxes. The physical properties of the snow layer in each specific case have to be given in order to determine the magnitude of this fraction. Combining this potential contribution, $\Gamma R_{\mathrm{S}_{0}}$, with the net long wave radiation at the surface $\Gamma R_{\mathrm{LN}}$ (Table 2 ) provides the potential values for the energy term. The potential energy term is reduced, or becomes negative, with increased albedo, $a$, and with reduced surface temperature. With $R_{\mathrm{s}}=200 \mathrm{~W} \mathrm{~m}^{-2}$, small and negative values are computed for the energy term, and even for $\boldsymbol{R}_{\mathrm{S}}$ $=500 \mathrm{~W} \mathrm{~m}^{-2}$ and $a=0.5$, the actual energy contribution to the surface balance may be negligible or negative.

Computation of the aerodynamic energy term in Equation (1) was made using a surface-layer similarity relation, and the approximation:

$$
\begin{aligned}
r_{\mathrm{a}}^{-1} \cong & u_{\mathrm{z}} k_{\mathrm{O}}^{2}\left[\ln \left(\frac{z}{z_{0}}\right)-\Psi_{\mathrm{M}}\left(\frac{z}{L}\right)\right]^{-1} \\
\times & {\left[\ln \left(\frac{z}{z_{0}}\right)-\Psi_{\mathrm{H}}\left(\frac{z}{L}\right)\right]^{-1}, }
\end{aligned}
$$

where $\quad z=$ the reference height above the surface (10 $\mathrm{m}$ in the present computations),

$\Psi_{M}$ and $\Psi_{H}=$ the integrated stability functions for momentum and heat/moisture transfer, respectively, $k_{0}=$ the von Karman constant, 
$u_{z}=$ the wind speed at a reference level $z$, $L=$ the Monin-Obukhov length.

Note that in Equation (4), the scaling roughness length for temperature/humidity, $z_{\mathrm{T}}$, is assumed equal to $z_{0}$ for convenience. The calculations presented here are little affected by this assumption.

Denoting $\zeta=z / L$ then:

$$
\Psi\left(\frac{z}{L}\right)=\int_{0}^{\zeta} \frac{1-\phi\left(\zeta^{\prime}\right)}{\zeta^{\prime}} \mathrm{d} \zeta^{\prime},
$$

where [e.g. Brutsaert (1982), pp. 68-71]:

$$
\begin{array}{cl}
\phi_{\mathrm{M}}^{2}\left(\frac{z}{L}\right)=\phi_{\mathrm{H}}\left(\frac{z}{L}\right)=\left(1-16 \frac{z}{L}\right)^{-1 / 2} & \text { for } \frac{z}{L}<0, \\
\phi_{\mathrm{M}}\left(\frac{z}{L}\right)=\phi_{\mathrm{H}}\left(\frac{z}{L}\right)=1+5 \frac{z}{L} & \text { for } \frac{z}{L} \geqslant 0 .
\end{array}
$$

Considering the aerodynamic energy term in Equation (1), a water vapor deficit in the air near the surface $\left(\delta q_{\mathrm{a}}\left(T_{\mathrm{s}}\right)<0\right)$, tends to result in evaporation, with a reduction in the contribution to $H_{\mathrm{s}}$. On the other hand, a water vapor surplus $\left(\delta q_{\mathrm{a}}\left(T_{\mathrm{s}}\right)>0\right)$ results in condensation on the snow surface which is most likely to occur for $T_{\mathrm{a}}>273 \mathrm{~K}$. So far as the surface roughness $\left(z_{0}\right)$ is concerned: two situations were considered: (1) a mobile surface is assumed, and the value for $z_{0}$ is obtained following Chamberlain (1983):

$$
z_{0}=0.016 u_{*}^{2} g^{-1}
$$

where $g$ is the gravity acceleration; and (2) a rough surface is assumed, with $z_{0}=0.05 \mathrm{~m}$ reflecting grass or bushes fully covered by snow.

Values of the aerodynamic energy term, with the negative sign, for $\left|\delta q_{\mathrm{a}}\right|=1 \mathrm{~g} \mathrm{~kg}^{-1}$ and for $T_{\mathrm{s}}=273 \mathrm{~K}$
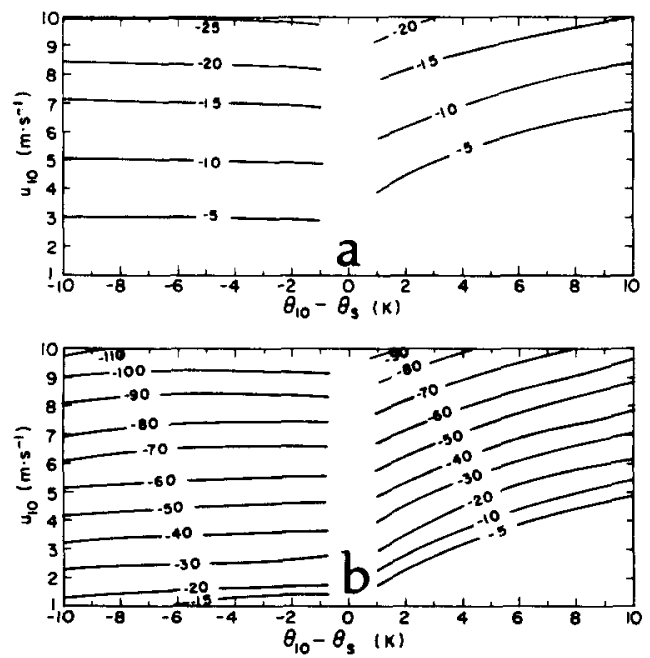

Fig. 1. Computed contribution to the sensible heat flux (W $\mathrm{m}^{-2}$ ) over snow surface by the aerodynamic term (second term in Equation (1)) for various combinations of $u_{10}$ and $\theta_{10}-\theta_{3}$. Snow surface temperature is assumed to be $273 \mathrm{~K},\left|\delta q_{\mathrm{a}}\right|=1 \mathrm{~g} \mathrm{~kg}^{-1}$; (a) $z_{0}$ given by Equation (7); and (b) $z_{0}=0.05 \mathrm{~m}$. are presented in Fig. 1 for various combinations of $\Delta \theta=\theta_{10}-\theta_{\mathrm{s}}$ (where $\theta_{10}$ and $\theta_{\mathrm{s}}$ are the potential temperatures at $10 \mathrm{~m}$ in the air and at the surface, respectively) and $u_{10}$. Worth noting is that with the increase in $|\Delta \theta|$ and $u_{10}$ the real world likelihood for both having large values is less. Values for the case of a mobile snow surface (Fig. 1a) are almost insensitive to the magnitude of $\Delta \theta$, and are also almost negligible for light winds in the stable surface layer. Comparing the computed values with those presented in Tables 1 and 2 for the energy term, suggest that the aerodynamic term may become of some importance for a snow surface with high albedo. When $z_{0}=0.05 \mathrm{~m}$, the computed values of the aerodynamic energy term in Equation (1) are somewhat higher than those computed in the previous case for light surface winds, and

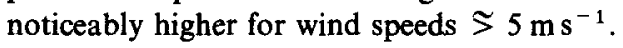

\subsection{Evaluations of $\mathrm{H}_{s}$ based on surface-layer characteristics}

Considerations in the previous subsection provide a physical understanding of the available energy partition involved with the generation of $H_{\mathrm{s}}$, although providing only general scaling in regards to the potential $H_{\mathrm{s}}$ values. Quantification of $H_{\mathrm{s}}$ values, based on assumptions relating to the possible surface-layer flow and thermal stratification over snow surfaces, is straightforward. Sensible heat fluxes over snow surfaces for various combinations of $u_{10}, \Delta \theta$, and $z_{0}$ were computed (with $\theta_{\mathrm{s}}=273 \mathrm{~K}$ ) from:

$$
H_{\mathrm{s}}=-\frac{\rho_{\mathrm{a}} C_{\mathrm{p}} \Delta \theta}{r_{\mathrm{a}}},
$$

where $r_{\mathrm{a}}$ is given by Equation (4); values are shown in Fig. 2.

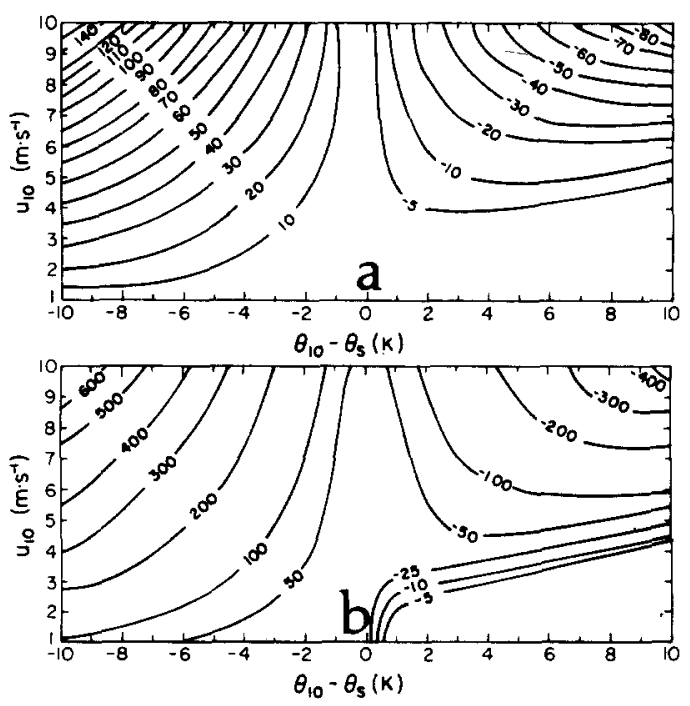

Fig. 2. Computed sensible heat fluxes, $H_{3}\left(\mathrm{~W} \mathrm{~m}^{-2}\right)$, over a snow-covered surface for various combinations of $u_{10}$ and $\theta_{10}-\theta_{s} ;$ (a) $z_{0}$ given by Equation (7); and (b) $z_{0}=0.05 \mathrm{~m}$. 
For a mobile snow surface (Fig. 2a) with cold advection near the surface, it is likely that $\Delta \theta \leqslant 0$, and the values of sensible heat flux in these situations, may reach values greater than $100 \mathrm{~W} \mathrm{~m}^{-2}$. In the stable surface layer, values of $\left|H_{s}\right|$ are lower than $10 \mathrm{~W} \mathrm{~m}^{-2}$ for light surface winds, increasing to $\approx 100 \mathrm{~W} \mathrm{~m}^{-2}$ for a surface wind speed of $10 \mathrm{~m} \mathrm{~s}^{-1}$ and $\Delta \theta=10 \mathrm{~K}$. For the larger surface roughness $\left(z_{0}=0.05 \mathrm{~m}\right.$; Fig. 2b), the computed values of $H_{\mathrm{s}}$ are higher compared to those computed over a mobile snow surface.

Observational values of $H_{\mathrm{s}}$ (e.g. Hicks and Martin, 1972; Granger and Male, 1978) suggest that, typically over a snow surface, $-50 \mathrm{~W} \mathrm{~m}^{-2} \lessgtr H_{\mathrm{s}} \lesssim 50 \mathrm{~W} \mathrm{~m}^{-2}$. These measurements are consistent with values computed for a uniform snow-covered area, although the observations of Granger and Male (1978) indicate occasionally larger values of $H_{\mathrm{s}}$ related to synoptic weather perturbations and air mass advection. On the other hand, as reported in typical winter situations, the values of $H_{\mathrm{s}}$ over dry bare soil are in the range $100-200 \mathrm{~W} \mathrm{~m}^{-2}$ (e.g. Hicks, 1981).

The implications of previous results to the dispersion potential of the $A B L$ are:

(1) the daytime surface layer over fresh and deep snow tends, in most cases, towards neutral or stable thermal stratification, resulting in suppressed turbulence;

(2) even when $H_{\mathrm{s}}$ fluxes over snow cover are positive (i.e. toward the atmosphere) they are likely to be small (unless in situations with a strong, cold flow), and the break-up of the surface nocturnal inversion is then ineffective; and consequently,

(3) the development of the daytime convective ABL is likely to be weak, and in most situations it will be reduced significantly when compared to that developed over snow-free ground under the same environmental conditions.

In many cases, advection of warm air over a snow surface (i.e. advected air temperature $>273 \mathrm{~K}$ ) from adjacent snow-free surroundings may occur. This flow should result in the development of a stable lower ABL (and consequently, downward sensible heat fluxes). Since the snow surface temperature is constrained to $273 \mathrm{~K}$, the thermal stabilization may on many occasions be extreme; such situations may occur: (1) in relatively southern latitudes; and (2) following early/ late season snow. Similar features were observed and modeled for warm offshore flow over relatively cold water bodies (e.g. Mahrer and Segal, 1979). Slade (1968) measured surface turbulence properties for analogous situations over the Chesapeake Bay, U.S. and found a significant suppression of the turbulence.

\section{EVALUATIONS OF THE SURFACE SENSIBLE HEAT FLUXES OVER NON-UNIFORM SNOW COVER}

Modification of the surface sensible heat flux as evaluated in section 2 , due to the existence of vegeta- tion or bare ground patches within a snow-covered area, or when an urban area is involved, is considered.

\subsection{Vegetation}

Snowfall over a vegetated area may, occasionally, cover the canopy significantly for a period of a few days. Eventually, it melts, or falls below the canopy and accumulates there. For a very dense canopy with a high shielding of solar radiation, the direct interaction of the snow on the surface with the atmospheric surface layer above the canopy is weak. Thus, the canopy-air interaction predominates (see the evaluation in Segal et al., 1991b). This is most commonly true for dense conifer forests (e.g. the Adirondacks of New York). Equation (1) can be used for the evaluation of $H_{\mathrm{s}}$ over a canopy covered by snow, with appropriate $z_{0}$ values adopted. As evaluated in the previous section, the only difference from the $H_{\mathrm{s}}$ values obtained for uniform snow cover over bare ground is related to the aerodynamic term (i.e. more negative values of sensible heat flux).

In areas affected by snow, air temperatures in the winter are generally below the threshold needed for stomatal opening, although transpiration in such areas would, in any case, be small. Dormant deciduous forests obviously lack transpiration during the winter, and when these are very dense, the shielding of solar radiation by the tree branches enables only a fraction of the diffuse solar radiation to reach the surface below. Dickinson et al. (1986) suggest that for dense deciduous forests the stem area index is about 2 , which implies that the projection on the ground of the tree stems and branches result in a total area which is doubled as compared to the underlying area below the tree. Assuming a dry non-transpiring canopy, the related values of $H_{\mathrm{s}}$ are similar to those over dry bare soil (e.g. Segal et al., 1989). Thus, in general, dispersion characteristics are to the first approximation similar to those over bare ground. Additional insight into situations involved with snow cover in forested and deforested areas can be found, for example, in Daugharty and Dickison (1982).

\subsection{Urban areas}

The study of pollutant dispersion is of major importance in the urban area. The snow surface uniformity, in such an area, is broken by buildings, vegetation, pavement, roads, etc. Therefore, modifications of the surface sensible heat flux features discussed in section 2 occur due to the presence of low albedo surfaces, resulting in higher surface temperatures and a related increase in the surface sensible flux into the atmosphere. Figure $3 \mathrm{a}$ presents the 8 February 1989, $1200 \mathrm{~h}$ MST (Mountain Standard Time) GOES visible imagery of the urban area of Denver, Colorado, following a snow storm on the previous day. It is very noticeable that the urban area appears relatively dark indicating the presence of nonuniform snow cover, while the surrounding area has uniform cover (the Denver Stapleton airport, which is 


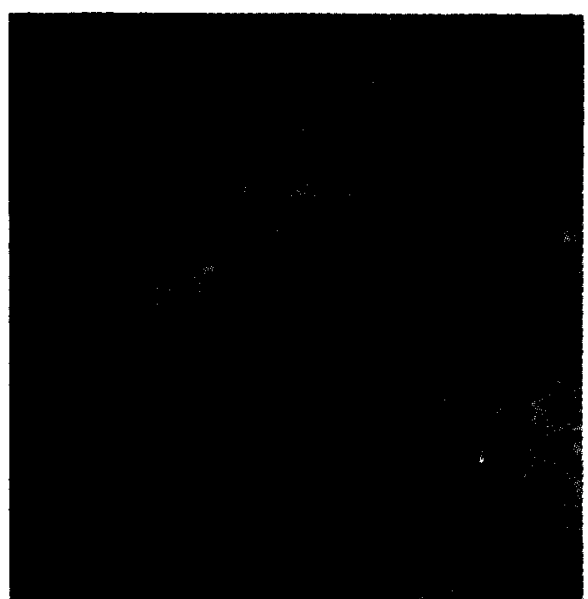

a

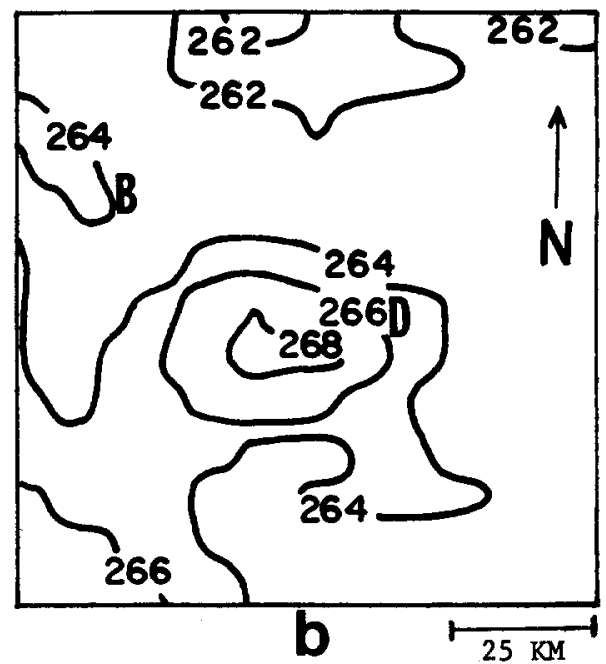

Fig. 3. (a) GOES visible imagery of the metropolitan area of Denver, CO, and its surroundings on 8 February 1989, $1200 \mathrm{~h}$ MST following a snow storm; and (b) GOES i.r. temperature for the area presented in (a). B-Boulder; DStapleton airport in Denver (located northeast of the center of the metropolitan area).

northeast of the metropolitan area of Denver, is indicated by $D$ ). The forested areas over the Rocky Mountains in the western portion of the domain also appear dark, indicating that most of the canopy surfaces were snow free. GOES i.r. surface temperatures taken at that time (Fig. 3b) indicate higher surface temperatures in the metropolitan area of Denver (reaching $268 \mathrm{~K}$ ) compared to the snow-cover surroundings which had temperatures as low as $262 \mathrm{~K}$. This feature implies a less stable thermal stratification in the lower atmosphere over the urban area compared to that over the surrounding snowcovered area.

A further indication of the possible impact of the non-uniform snow cover in the urban area upon the surface sensible heat flux is provided through Fig. 4. Measurements of the temperatures of various surfaces, using a Teletamp portable infrared thermometer (Model AG-42) and measurements of the air temperature at a height of $\approx 1.5 \mathrm{~m}$ above ground (using an aspirated portable thermometer), were carried out during the winter of 1987-1988 at the Foothills Campus of Colorado State University in Fort Collins. The measurements were made over predominantly snowcovered grounds, usually under clear sky and light wind conditions. As shown in Fig. 4, the surface temperatures of the various snow-free surfaces were higher than those of the snow surface (therefore, implying an increased surface sensible heat flux into the atmosphere). Specifically, the measurements indicated the following:

(1) the snow surface temperatures were at least several degrees $\mathrm{K}$ lower than the measured air temperature at $1.5 \mathrm{~m}$, indicating a surface temperature inversion. The intensity of the temperature inversions were mostly pronounced during the relatively warm days;
(2) the non-vegetated surfaces (e.g. asphalt road, bare soil, building walls, gravel, pavement, etc.) were associated with higher surface temperatures by at least several degrees $\mathbf{K}$ compared with the snow surface, and occassionally reaching differences higher by $20 \mathrm{~K}$. Also, on many occasions, these surfaces tended to be warmer than the air temperature by a significant amount;

(3) the canopy temperature on the sunlit side of evergreen trees exceeded the air temperature by no more than a few degrees $\mathrm{K}$, while the shadowed side was generally a few degrees $K$ lower than the air temperature. The higher temperatures of the deciduous tree trunks, relative to the air temperature, are particularly evident.

The features listed in (1)-(3) document further the impact of snow cover on the surface sensible heat flux in an urban area.

\section{EVALUATION OF DAYTIME DISPERSION CONDITIONS OVER SNOW COVER}

\subsection{Surface dispersion}

An indication of the impact of snow cover on surface daytime dispersion can be qualitatively provided using, for example, Turner's (1964) and PasquillGifford's stability classification. These classifications are based on: (1) the surface wind speed, which is altered somewhat over snow cover; and (2) the solar radiation at the surface (expressed through a radiation index), which actually affects the magnitude of $H_{s}$. As determined in the previous section, the daytime values of $H_{s}$ over uniform snow cover are negligible, on many occasions. This should result in a shift of the stability 


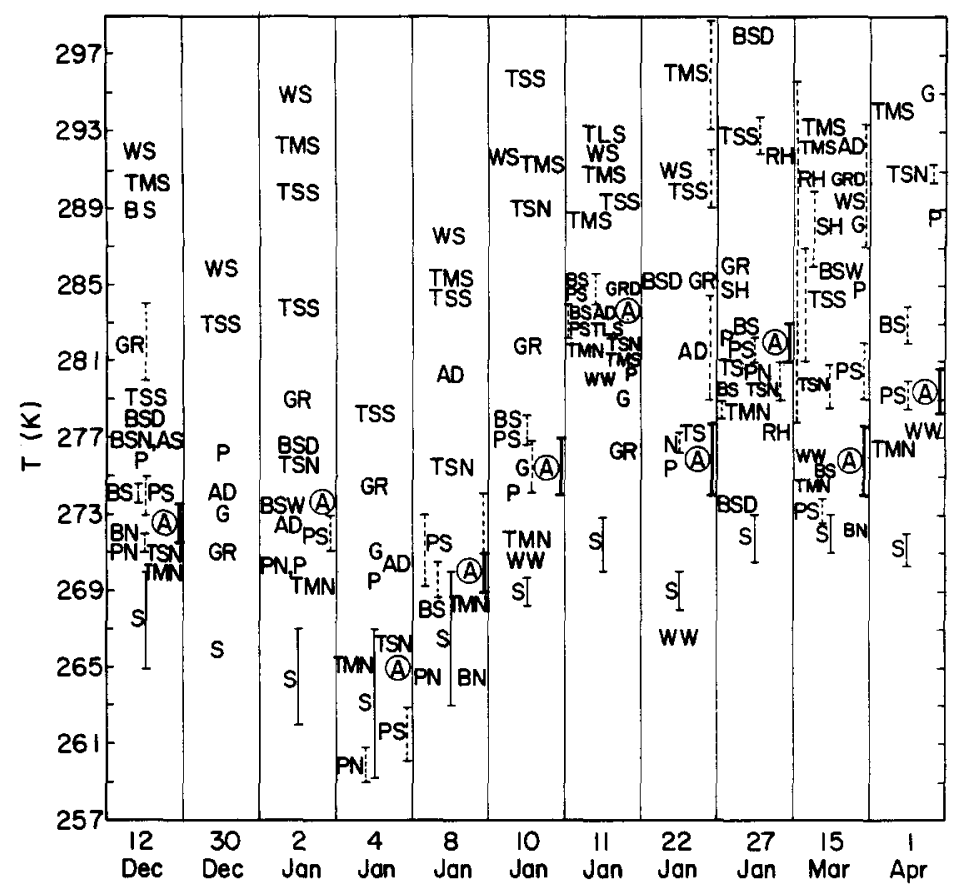

Fig. 4. Surface temperature of various surfaces measured around noon during the winter of 1987-1988 at the Foothills Campus of Colorado State University during days with snow-covered ground. The following surfaces were considered: AD-dry asphalt; BN and BS-blue spruce north and south facing canopy, respectively; BSD and BSW-dry and wet bare soil, respectively; G-gravel; GR - grass; P-pavement; PN and PS - pine north and south facing canopy; RH - horizontal surface of rock; TMN and TMS - medium tree trunk, north and south facing, respectively; TSN and TSS-small tree trunk, north and south facing, respectively; WN, WS and WW-building north, south and west facing walls, respectively. $S$ indicates the snow surface temperature and $A$ the air temperature at $1.5 \mathrm{~m}$, where the range of these temperatures is indicated by dark lines. The measurements were taken following noon (1200-1330 h MST). On 4, 10 and 11 January some temporary cloudiness appeared during the measurements period. Windy conditions occurred with the 11 January case.

classification towards more stable classes. It is suggested that a modified version of the above stability classifications over uniform snow cover can be established for daytime dispersion by replacing the radiation index with a snow albedo index when $T_{\mathrm{s}}<273 \mathrm{~K}$. On warm days when the air temperature, $T_{\mathrm{a}}$, is greater than $273 \mathrm{~K}$, typically $T_{\mathrm{s}} \cong 273 \mathrm{~K}$. In this case a replacement by a temperature index $\left(T_{\mathrm{a}}-273\right)$ is likely to be appropriate.

The impact of snow cover on the surface-layer turbulent dispersion can be quantified following Golder (1972), by computing the value of $L^{-1}$, which is given by:

$$
L^{-1}=-\frac{k_{0} g H_{\mathrm{s}}}{C_{\mathrm{p}} \rho_{\mathrm{a}} \theta u_{*}^{3}},
$$

where $u_{*}$ is the surface friction velocity. Golder (1972) provides a relation between $L^{-1}, z_{0}$ and the aforementioned stability classes. For the unstable surface layer with an increase in $L^{-1}$, the stability dispersion class tends to be less unstable. As found in the previous section, the reduction of $H_{\mathrm{s}}$ over uniform snow cover, compared to bare ground conditions, is significant while the corresponding impact on $u_{*}$ is probably secondary. This implies a tendency toward a significant decrease in $L^{-1}$ over snow, and a stabilization of the dispersion classes, compared to those related to bare ground under the same overlying environmental conditions. It is worth noting that Segal et al. (1990) found (while using this approach) that the impact of possible changes in surface wetness results at most in a one class shift in the Pasquill-Gifford stability classification during the daytime.

\subsection{Depth of the daytime unstable $A B L$}

In this subsection, we evaluate the daytime depth of the ABL over snow, assuming slightly unstable surface-layer conditions. This depth, together with the wind speed, provide a general indication for the daytime dispersion conditions. Quantification of the time dependent depth of the ABL, $h(t)$, when the 
surface layer is unstable can be approximated by (e.g. Tennekes, 1973):

$$
h(t)=\left[\frac{2 \int_{0}^{t} H_{\mathrm{s}} \mathrm{d} t^{\prime}}{\rho C_{\mathrm{p}} \frac{\partial \theta_{0}}{\partial z}}\right]^{1 / 2},
$$

where $\partial \theta_{0} / \partial z$ is the early morning, environmental vertical $\theta$ gradient in the lower atmosphere.

As evaluated in the previous section, stable daytime surface layers are likely to be typical on many occasions over uniform fresh snow cover. However, in the presence of advection of relatively cold air over a snow surface, or due to the existence of bare ground patches or vegetation, an upwards sensible heat flux into the atmosphere over such an area will result. Consequently, the development of a shallow and slightly unstable ABL should occur.

Illustration of the daytime development of the ABL, using Equation (10), is given in Fig. 5. We considered a sinusoidal temporal variation of $H_{s}$ with a peak value at noon, $H_{\mathrm{s} 0}$ and a day period of $9 \mathrm{~h}$. The values of $\boldsymbol{H}_{\mathrm{so}}$ vary from $10 \mathrm{~W} \mathrm{~m}^{-2}$ (reflecting, for example, mild cold air advection, or snow cover with scattered bare ground patches) to $80 \mathrm{~W} \mathrm{~m}^{-2}$ (reflecting, for example, an increased area of bare ground patches). Note that under dry, bare ground conditions, $H_{s}$ values during sunny winter days in mid-latitudes may reach 150 $200 \mathrm{~W} \mathrm{~m}^{-2}$ (e.g. Hicks, 1981). In the computations, we considered $\partial \theta_{0} / \partial z=0.1 \mathrm{~K} \mathrm{~m}^{-1}$ (i.e. a relatively strong stable lower atmosphere in the early morning hours). The range of the daytime computed $\mathrm{ABL}$ depths, generally, indicates low vertical pollutant mixing potential. Using Equation (10) and Fig. 5, one can estimate the ABL depth obtained while modifying values of $H_{\mathrm{s} 0}$ and $\partial \theta_{0} / \partial z$, compared to those assumed in the computations presented in Fig. 5. For example, assuming $H_{\mathrm{so}}=240 \mathrm{~W} \mathrm{~m}^{-2}$ as a possible maximum noon hour surface sensible heat flux over bare ground, with the same $\partial \theta_{0} / \partial z$ used in the computation of Fig. 5, results in an ABL depth larger by $\sqrt{3}$ as compared to that computed with $H_{\mathrm{s} 0}=80 \mathrm{Wm}^{-2}$.

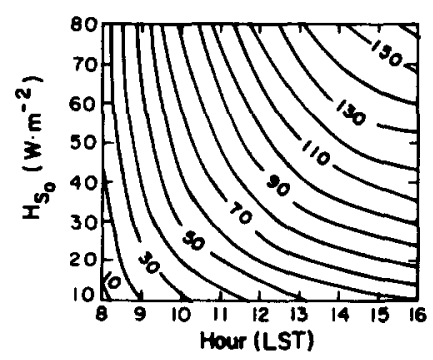

Fig. 5. The depth of the ABL (in m) as a function of the noon surface sensible heat flux, $H_{\mathrm{so}}$, and the hour of the day.

\section{OBSERVATIONS OF THE ABL CHARACTERISTICS OVER SNOW}

In section 4, scaling and conceptual evaluations of the snow effect on the ABL characteristics were provided; observational results are presented in this section. Vertical temperature profiles observed at a meteorological tall tower, radiosonde profiles, and aircraft measurements are analyzed and described, illustrating these ABL characteristics (thermal stratification and turbulence) which affect pollutant dispersion over snow cover. These characteristics are compared to those measured in snow-free ground conditions under similar environmental conditions.

\subsection{Boulder Atmospheric Observatory $(B A O)$ meteoro- logical tower temperature profiles}

The BAO meteorological tower is located along the Front Range of Colorado near Erie $105.25^{\circ} \mathrm{W}$; $40.02^{\circ} \mathrm{N}$. Its height is $300 \mathrm{~m}$ and the measurement levels are located at $10,22,50,150,200,250$ and $300 \mathrm{~m}$ above ground. The general terrain features at the tower area consist of the Rocky Mountains to the west and the High Plains to the east. The Front Range of Colorado is frequently affected by snow during the winter, and usually the snow cover persists for a period of several days. Occasionally, longer periods are observed. During the winters of 1986-1987 and 1987-1989 daytime profiles of temperatures were collected for snow covered days and for the following days when the ground was snow free. These days were synoptically unperturbed, with relatively light synoptic flows and clear sky conditions. Generally, a trend towards thermal stabilization of the atmosphere was observed during the snow-covered days as opposed to a relatively deep neutral stratification for the snowfree ground cases. Illustrations of two typical profiles are provided in Fig. 6. Figure $6 \mathrm{a}$ presents an intense daytime surface inversion which apparently was related to the advection of warm stable air over the area, causing some general warming of the air over the snow in the morning hours. Corresponding temperature profiles over the bare ground, following the snow melt (Fig. 6b), reflect the development of a slightly convective $A B L$ during the daytime hours. Figures $6 c$ and $6 d$ provide a similar comparison, however, for a situation of less pronounced stable stratification over the snow cover. During the daytime a near-neutral boundary layer developed over the snow-free ground, with an implied development of a relatively deep convective $A B L$ over the snow-free ground.

\subsection{Radiosonde temperature profiles}

Examining the U.S. National Weather Service (NWS) temperature profiles during the winter of 1987-1988 indicated, in many cases, a significant undeveloped daytime ABL over snow-covered areas. An illustration of this situation is given in Fig. 7 for a deep snow cover event at Amarillo, Texas, for which 

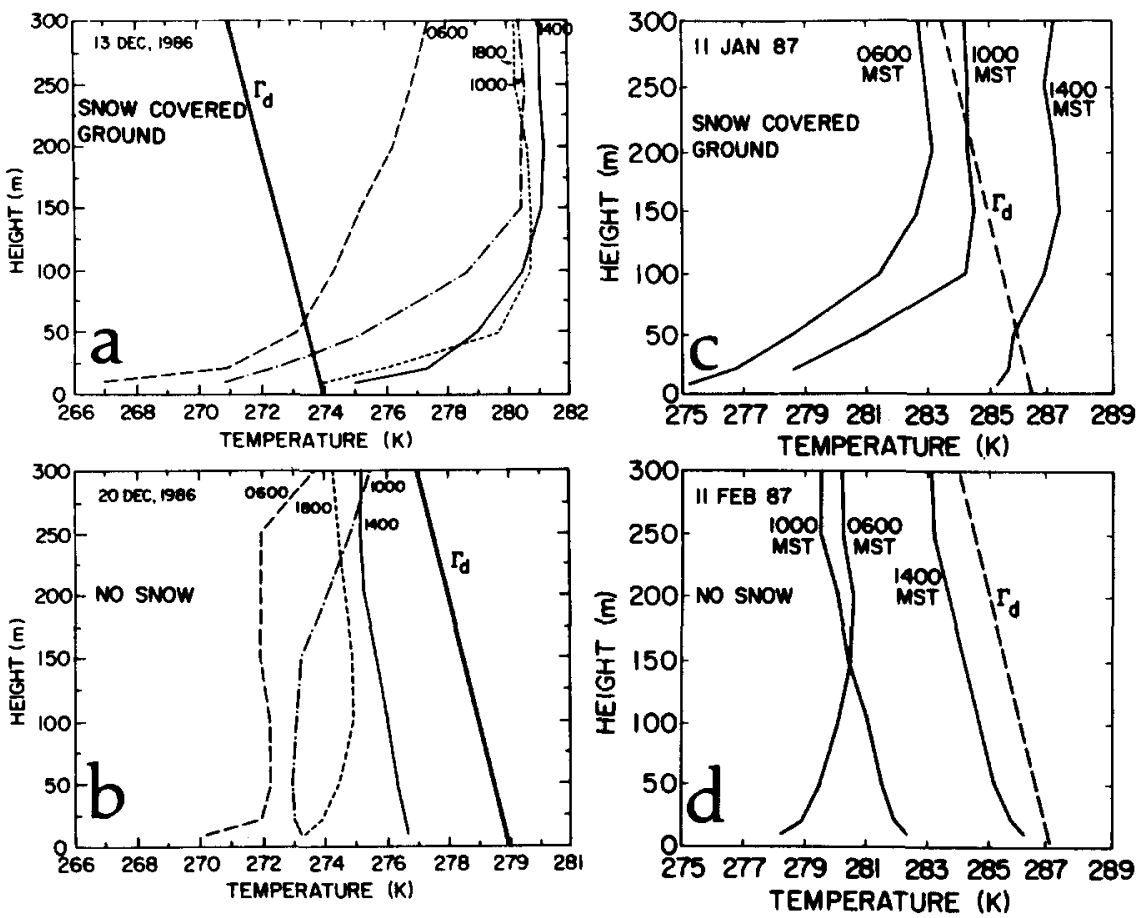

Fig. 6. Air temperature profiles from the BAO $300 \mathrm{~m}$ meteorological tower located near Erie, Colorado: (a) over snow cover (13 December 1986); (b) over snow-free ground (20 December 1986); (c) over snow cover (11 January 1987); and (d) over snow-free ground (11 February 1987). $\Gamma_{\mathrm{d}}$ represents the dry adiabatic lapse rate. The plotted temperatures are 20-min averaged values. Profiles are labeled in MST (Mountain Standard Time).

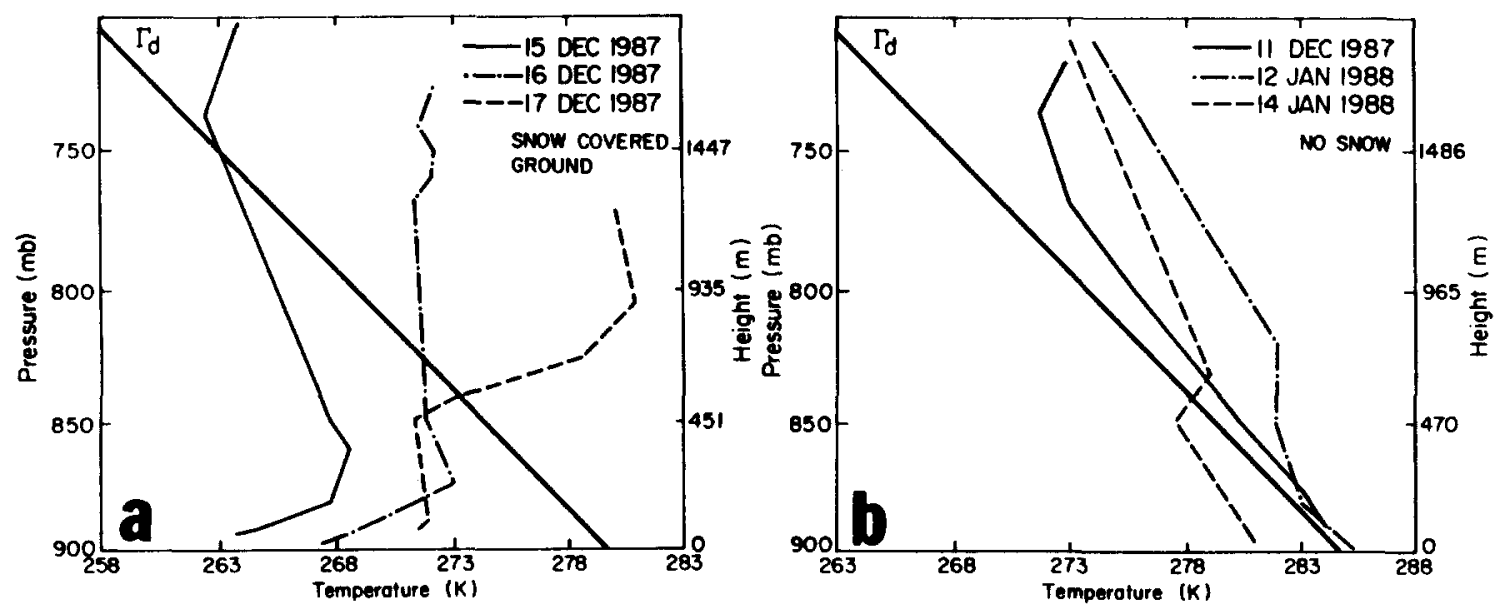

Fig. 7. NWS radiosonde temperature soundings for Amarillo, Texas: (a) over snow-free ground; and (b) over snow cover. The sounding time for all profiles is $1800 \mathrm{~h}$ CST (Central Standard Time). $\Gamma_{d}$ represents the dry adiabatic lapse rate (the height axis is approximated using the hydrostatic equation).

temperature profiles, when the ground was snow free and where the ground was snow covered, are compared. The transition from a relatively deep daytime slightly convective boundary layer over snow-free ground to a stable ABL during the snow-covered ground period is evident (generally, clear sky conditions were typical throughout both periods). The deep thermally stable lower atmosphere is commonly generated due to advection of a stable air mass, or as a result of subsidence after the preceding snow precipitation event. As evident from the Fig. 7a, during the daytime with snow cover present, the development of even a shallow neutral ABL is prevented, apparently due to the suppressed sensible heat fluxes over the 
snow cover. In contrast, when the ground is snow free in the same period of the year, a daytime ABL depth of several hundred meters occurs (Fig. 7b).

\subsection{Aircraft measurements}

During the SSBLIM (Snow Shading Boundary Layer Interaction Measurements) project, which was carried out in Colorado and Northern Texas in the winter of 1988, aircraft measurements of temperatures were taken over a snow-covered area and an adjacent snow-free ground within a short span of time. These measurements provided an opportunity to examine the daytime ABL structure over both surfaces under similar environmental conditions; details of the ex-
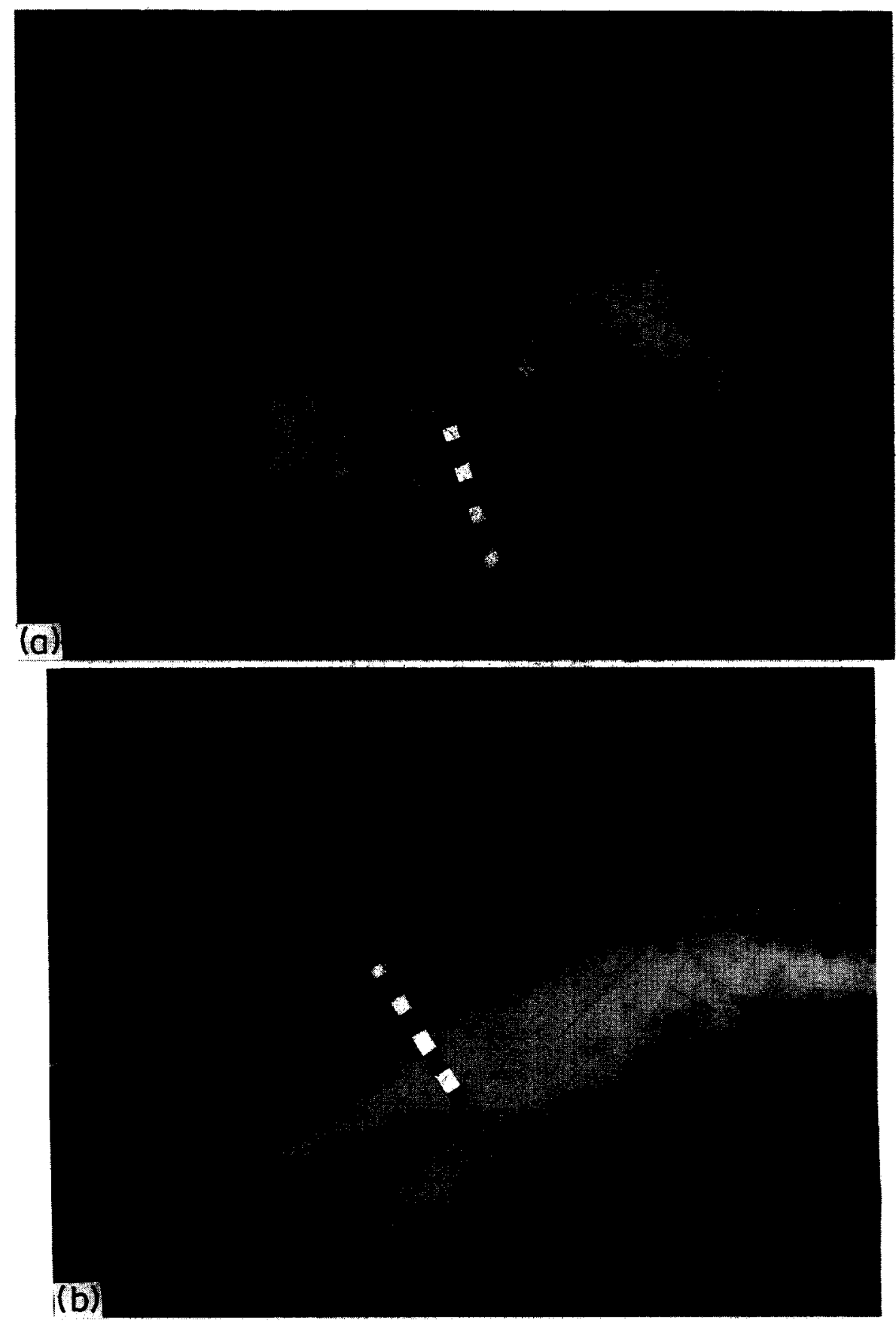

Fig. 8. GOES visible imagery and flights transects (indicated by the black-white line): (a) on 12 February 1988, $1132 \mathrm{~h}$ MST southeast Colorado (PUB - Pueblo, COS-Colorado Springs, LHXLa Junta); and (b) on 19 March 1988, $1647 \mathrm{~h}$ CST over the northeast portion of the panhandle of Texas and northwest Oklahoma (LBL-Liberal). 
periment, technical aspects, data processing methods, and the synoptic conditions are presented in Cramer (1988).

Detailed ABL measurements made by aircraft are provided below for two flights: (i) Flight \#1 (12 February 1988, in the vicinity of La Junta, Colorado) and (ii) Flight \#2 (19 March 1988, over the northern panhandle of Texas; south of Liberal (LBL), Kansas to the north of Hemphill County (HHF), Texas). GOES visible imagery indicating the extent of the snow area and the aircraft transect locations for the two flights are shown in Fig. 8; detailed observations taken during these flights can be found in Cramer (1988). The related terrain elevation change and the surface albedo in Flight \#1 and Flight \#2, are provided in Fig. 9. The albedo over the snow-covered areas reached values of 0.7 , as compared to 0.2 over the snowfree ground. Figure 10 provides a vertical crosssection of the potential temperature along the flights transects. This is based on flight altitudes of 95,180 , 340 and $710 \mathrm{~m}$ in Flight \#1, and 100, 180, 270 and $450 \mathrm{~m}$ in Flight \#2. The differentiation in the ABL characteristics between both surfaces is noticeable; i.e. a tendency towards a neutral lower atmosphere over the bare ground surface compared with a stable lower atmosphere over the snow (Fig. 10). In Flight \#1 the lower $800 \mathrm{~m}$ layer is nearly neutral for the section $0-12 \mathrm{~km}$. In Flight \#2 the neutral stratification is gradually established while moving away from the snow segment. It is likely that this spatial variation reflects the effect of a wet surface (due to previous snow melt) on the boundary layer. Note that since the
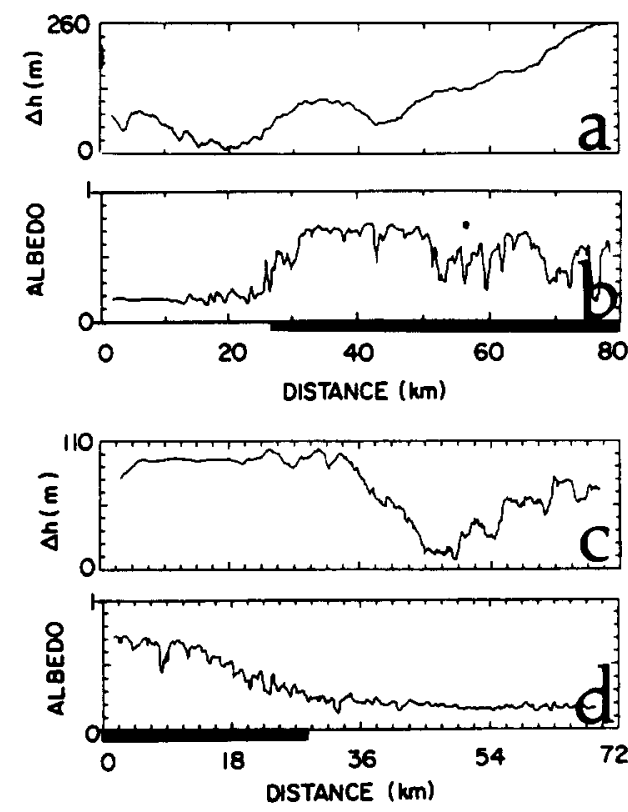

Fig. 9. Terrain elevation, $\Delta h$, variations and surface albedo along the flight transects indicated in Figs 8a and 8b. (a, b) 12 February 1988 flight (Flight \# 1); and (c, d) 19 March 1988 flight (Flight \#2). The snow section is indicated by a dark line. snow-covered section has a surface temperature of $\approx 273 \mathrm{~K}$ (implying a surface potential temperature, for $p=900 \mathrm{mb}$, of $\approx 283 \mathrm{~K}$ ) an intense surface inversion (unresolved by the aircraft measurements) should be assumed.

The approximated turbulent vertical velocity, $w^{\prime}$, for both flights along the aircraft transects, is given in Figs 11 (Flight \#1) and 12 (Flight \#2). It provides a general indication as to the suppression of the vertical and horizontal dispersion of pollutants over snow cover. In both flights, the suppression of its intensity over the snow-covered segment, as compared to that over the bare ground, is very noticeable. The values of

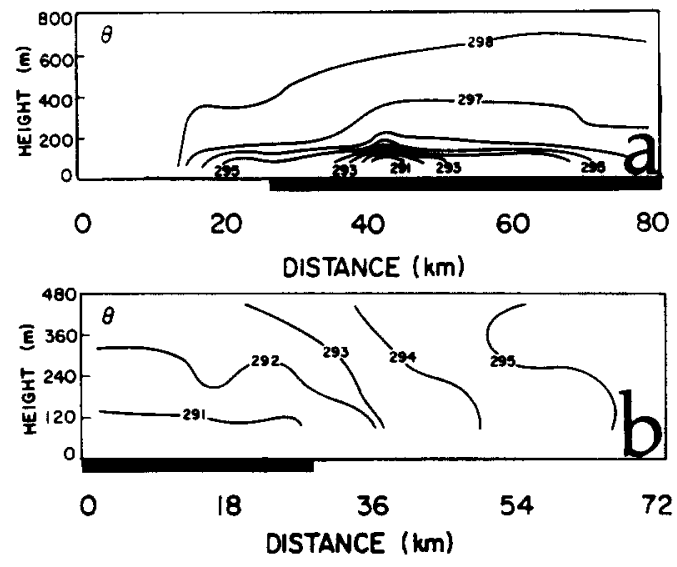

Fig. 10. Potential temperature along the transects indicated in Figs 8a and 8b. The snow section is indicated by a dark line. (a) Flight \# 1; and (b) Flight \# 2.

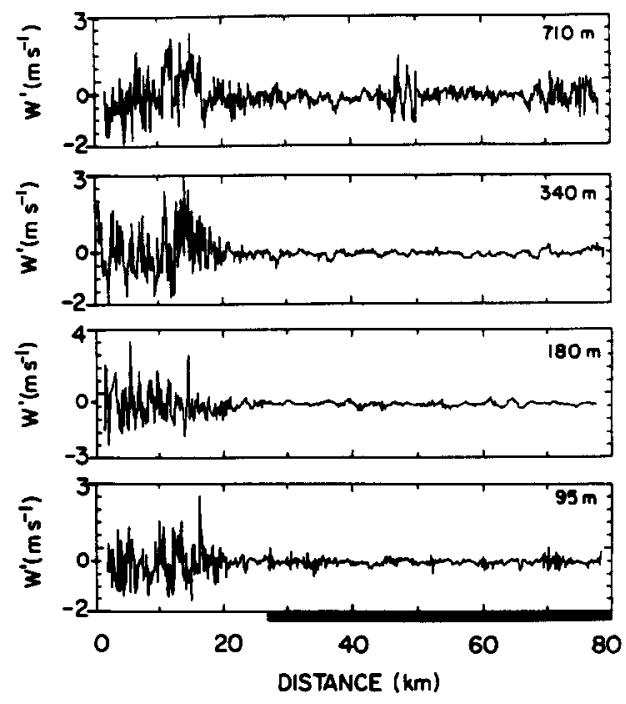

Fig. 11. The approximated turbulence vertical velocity for Flight \# 1 at various elevations along the transect indicated in Figs 8a and 8b. The snow section is indicated by a dark line. 


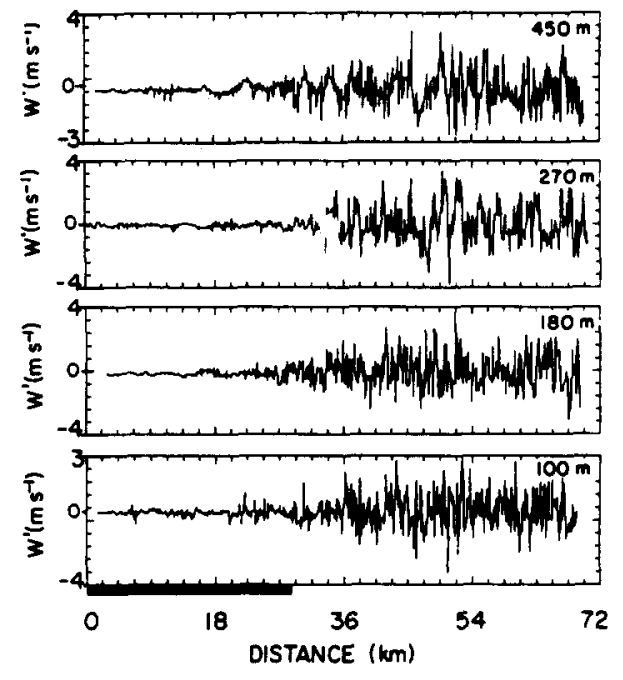

Fig. 12. As in Fig. 12, except for Flight \#2.

$w^{\prime}$ over the snow-free ground were frequently \pm 1.5 $\mathrm{ms}^{-1}$, whereas over the snow-covered section they were at least one order of magnitude smaller.

\section{ATMOSPHERIC PARTICLE CONCENTRATIONS}

\subsection{Aircraft observations}

Atmospheric particle concentrations (emitted from urban areas, local fireplaces, industry activity, fallow fields, dirt roads, etc.) were measured during the SSBLIM flights using a Particle Measuring Systems scattering spectrometer probe. Particles which are advected into the snow-covered area from the vicinity of the snow-bare ground boundary are limited in their vertical dispersion, as the turbulence over the snow is highly suppressed within the lower atmosphere. Consequently, their concentration is higher, as compared to the corresponding concentrations over the bare ground segment of the transect where a convective ABL is typical. In Flight \# 1 the background flow was southerly (nearly along the transect direction and toward the snow area) with typical wind speeds below $5 \mathrm{~m} \mathrm{~s}^{-1}$ in the lower flight legs ( $95 \mathrm{~m}$ and $180 \mathrm{~m}$ ). For the upper two legs the flow speed typically exceeded $5 \mathrm{~m} \mathrm{~s}^{-1}$. In Flight $\# 2$ the background flow was northwesterly (along the flight transect and toward the snow area) with wind speeds above $10 \mathrm{~ms}^{-1}$. Figure 13 presents the observed particle concentrations for Flights \#1 and \#2. Since the flights were carried out over rural areas, relatively few local sources for atmospheric particles should be assumed. Nonetheless, the results suggest a somewhat increased concentration level of atmospheric particles to the snow-covered area as compared to the snow-free area.

Evaluations relating to the impact of snow-covered surfaces on atmospheric particle concentrations in the vicinity of urban areas are given in Flight \#3 (17 February 1988). Aircraft measurements, with a flight
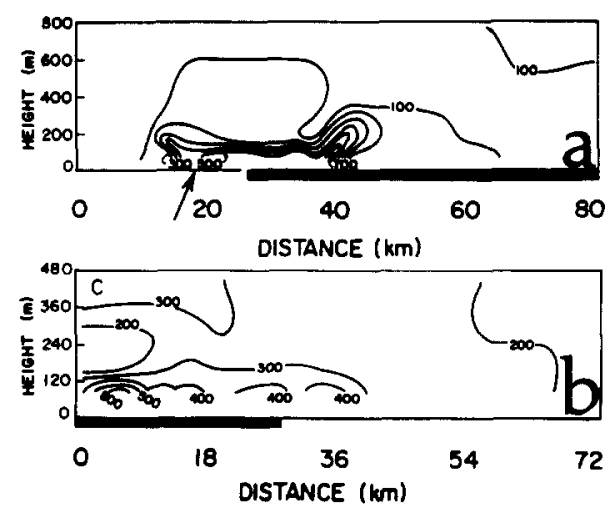

Fig. 13. $x-z$ cross-section analyses of the atmospheric particle concentrations (in particles per $\mathrm{cm}^{3}$ ) based on the aircraft measurement indicated in Figs $8 \mathrm{a}$ and $8 \mathrm{~b}$. The snow section is indicated by a dark line. speed of $\approx 80 \mathrm{~m} \mathrm{~s}^{-1}$, were carried out along the northern Front Range of Colorado (where the flight transects were between $40.2^{\circ} \mathrm{N} ; 104.95^{\circ} \mathrm{W}$ and $40.65^{\circ} \mathrm{N}$; $104.85^{\circ} \mathrm{W}$ as shown in Fig. 14). The measurements were repeated along this transect, however, at different times and altitudes. The area is about $50-100 \mathrm{~km}$ north of the metropolitan area of Denver, and in the vicinity of several towns (Boulder, Longmont, Greeley and Fort Collins). Contribution of urban sources to the particle concentrations measured is likely as a result of the prevailing south-southwesterly wind of about $5 \mathrm{~m} \mathrm{~s}^{-1}$ (along the flight transect) during the measurements. The southern portion of the transect was covered with snow (occasionally patchy), whereas its northern part was snow free; the albedo of the uniform snow cover was in the range $0.4-0.55$. In Fig. 15 the snow covered segment is implied by an increase in the albedo and by a relative decrease in the observed surface temperature. Since the snow cover area was not uniform at its edges, surface temperatures somewhat higher than $273 \mathrm{~K}$ are indicated for the partially snow-covered area.

The flight section between 1240 and $1253 \mathrm{~h}$ MST is over a snow-covered surface [as indicated by the increased albedo (Fig. 15a) and the reduced surface temperatures; Fig. 15b]. The variation of the aircraft altitude above the snow is also given (Fig. 15a). The corresponding measured particle concentrations are given in Fig. 15c. While the particle concentrations are relatively low between 1230 and 1240 h MST with a flight height of $\approx 180 \mathrm{~m}$ above ground over bare ground, they increased significantly over the snowcovered area. Following $1253 \mathrm{~h}$ MST, as the aircraft crossed to the lower albedo and warmer surface over the bare ground, particle concentrations dropped (note, however, the increase in the flight height which usually also involved a reduction in the concentrations). For the 1400-1430 h MST flight as indicated by Figs $15 \mathrm{~d}$ and $15 \mathrm{e}$, snow surfaces are involved with the 


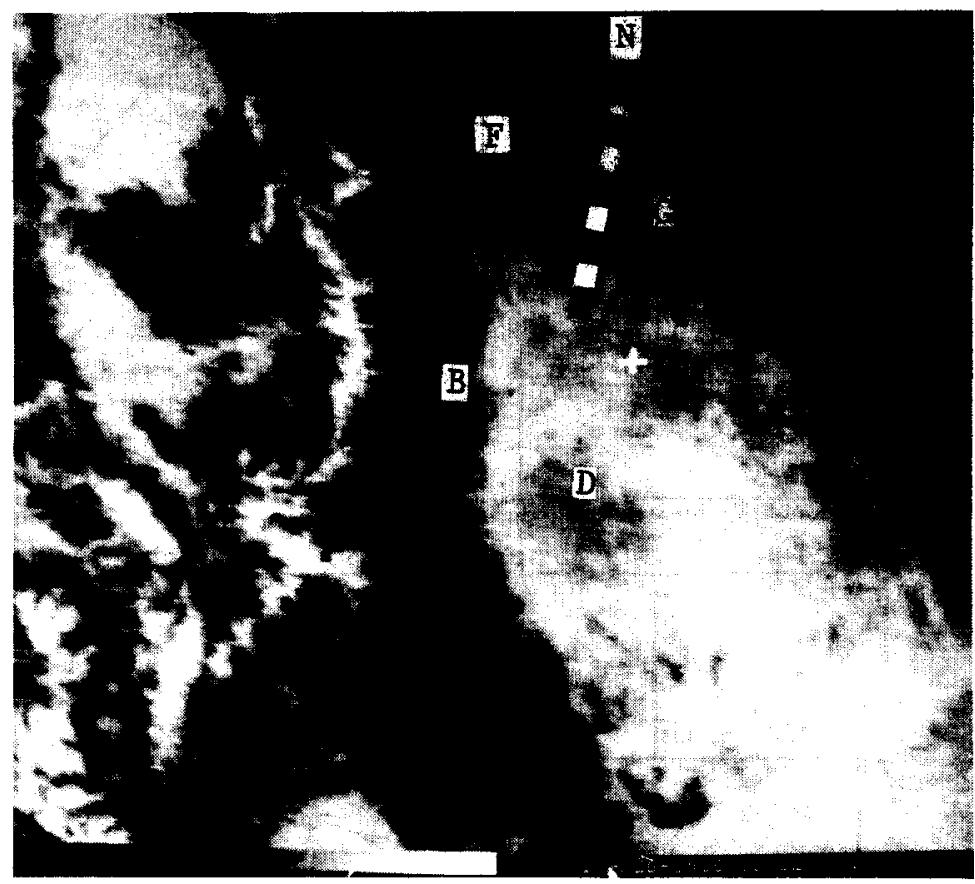

Fig. 14. GOES visible imagery and flights transects (indicated by the black-white line) on 17 February 1988, 1300 h MST (Flight \# 3); B-Boulder; F-Fort Collins; D-Denver Stapleton airport; G-Greeley; and N-Nunn.
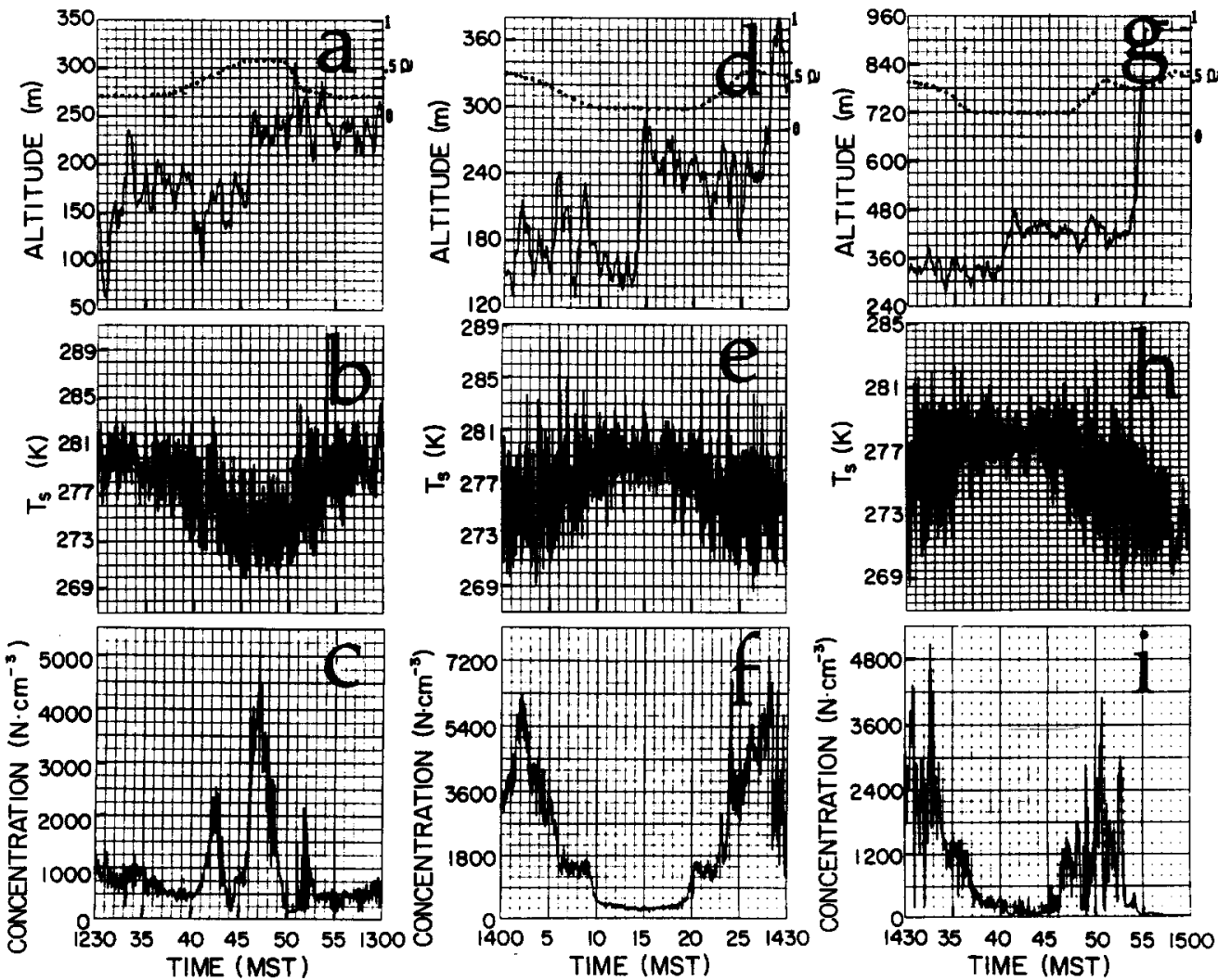

Fig. 15. Illustration of several characteristics involved with Flight \#3 (flight transects are indicated by the black-white line in Fig. 14) as dependent on time: (a) fight altitude (solid curves) and albedo, $a$ (dotted curves); (b) surface temperature $\left(T_{\mathrm{s}}\right.$ ); and (c) atmospheric particle concentrations (particles $\mathrm{cm}^{-1}$ ). Measurements during 1230-1300 h MST; (d), (e), (f) and (g), (h), (i) are the same as (a), (b), (c) except for the measurements during $1400-1430 \mathrm{~h}$ MST and 1430-1500 h MST, respectively. 
beginning of the flight period and toward the end of the flight period. Also, the aircraft altitude generally increased toward the end of the flight period (Fig. 15d). The particle concentration variations along the period (Fig. 15f) correlate with the snow coverage, regardless of the change in the flight altitude

In the third case (1430-1500 h MST), snow covered sections were observed at the beginning and the last third of the flight period (Figs $15 \mathrm{~g}$ and $15 \mathrm{~h}$ ). The particle concentration increases were measured over the snow section at the beginning of the flight, reducing substantially over the snow-free segment and increasing again over the snow cover (Fig. 15i). The increase of the flight altitude was significant towards the end of the period (Fig. 15g) resulting in a sharp drop in particle concentrations.

\subsection{Preliminary evaluation of snow cover and surface} pollutant levels in Denver, Colorado

The Air Pollution Control Division (APCD) of the Colorado Department of Health maintains an archive on pollutant levels in the Denver metropolitan area. The APCD determines the Pollutant Standards Index (PSI) for carbon monoxide (CO) and ozone on a continual hourly basis. The PSI equates pollutant levels to a fixed scale ranging from 0 to 500 . Any PSI value above 100 indicates that a National Ambient Air Quality Standard (NAAQS) for the pollutant in question has been reached. For ozone, the NAAQS is $0.120 \mathrm{ppm}$ hourly average. For CO, the NAAQS of concern is the 8-h standard of $9 \mathrm{ppm}$.

A major elevated pollution level period in Denver generally covers the mid-November-February time period. Therefore, PSI records were examined for 15 November-28 February of each pollution season (1985-1986, 1986-1987, 1987-1988), in conjunction with National Weather Service (NWS) daily snow cover and snowfall records from the Denver Stapleton international airport.

PSI data were initially segregated into two data sets, one in which ozone produced the daily maximum PSI value and the other where $\mathrm{CO}$ produced the daily maximum PSI value. These two subsets of PSI data were then compared to the NWS snow cover and snowfall data for the corresponding days.

Results of this analysis indicated for this winter period that, of the days when the maximum daily PSI was due to ozone, $63 \%$ had snow on the ground and fresh snowfall within the previous $48 \mathrm{~h}$. For the five highest daily ozone readings during the study period, four had snow on the ground and fresh snowfall within the previous $48 \mathrm{~h}$.

Due to the ubiquitous nature of $\mathrm{CO}$ in the winter urban Denver atmosphere, the analysis method for $\mathrm{CO}$ differed slightly from that of ozone. The subset of days in which CO produced the daily maximum PSI value was reduced to the days when the PSI value was above $100(>9 \mathrm{ppm} \mathrm{CO})$ and above $200(>15 \mathrm{ppm}$ $\mathrm{CO}$ ). Of the 83 total days when the daily maximum
CO value exceeded $9 \mathrm{ppm}, 57$ days (69\%) had snow on the ground. For the 23 days, when $\mathrm{CO}$ values exceeded $15 \mathrm{ppm}, 16$ days $(70 \%)$ had snow on the ground. These data should be contrasted to $56 \%$ of the days within the total three year study period that were snow covered.

The data presented suggest a possible relationship between snow-covered ground and elevated pollution readings. The pollution levels on these days are likely to be influenced by a stably stratified ABL which is especially pronounced when the ground is snow covered. Further study of the microclimatic conditions on these days and the potential for stable stratification of the ABL would seem justifiable, and may lead to a better understanding of elevated pollution readings during winter conditions in metropolitan Denver.

\section{DISCUSSION}

The impact of daytime uniform snow cover on the lower atmosphere, and on pollutant dispersion characteristics, was evaluated from relevant formulations and observations of the ABL thermal stratification, turbulence, and particle concentrations. Qualitatively in extreme cases, the snow-cover impact on dispersion conditions around noon may resemble, to a large extent, that involved with clear sky bare soil nocturnal conditions. However, in most cases, it is likely to resemble dispersion conditions prevailing during the early morning hours over bare ground. Non-uniform snow cover, such as that which occurs over urban/vegetated areas or when bare soil patches are generated during the snow melting period, reduces the impact described for uniform snow cover. Keeping in mind that the impact of snow cover on pollutant dispersion is variable and is dependent on its degree of uniformity, the evaluations presented in this paper suggest the following influences.

(1) Retarded daytime dispersion of surface emissions over snow-covered areas when compared to that over bare and dry ground under the same environmental conditions. This trend was suggested by a preliminary analysis of the Denver area surface concentrations of $\mathrm{CO}$ and ozone. Thus, assuming very extensive areas covered with snow, including large urban areas, surface emissions may be advected over relatively large distances over the snow while retaining their high concentrations.

(2) Improved local daytime surface pollution concentrations over snow-covered areas from such elevated source emissions as power plant tall stacks. In these cases, if the surface temperature inversion is below the plume, the pollutants do not reach the ground in high concentrations in the vicinity of the source. Likewise, when the surface inversion is deep, and the plume is emitted within it, the plume 
will be advected within a stable layer during the day and, thus not fumigated downward. In this situation, over bare ground with the same environmental conditions, the plume is likely to fumigate downward as the temperature inversion breaks up. Observational studies (e.g. Uthe et al., 1980) suggest that plumes emitted within highly stable layers can travel hundreds of kilometers, with only minor vertical spread due to suppressed turbulence.

(3) During the southward penetration of Arctic air masses in the winter, the atmosphere acquires a deep and strong thermally stable stratification in the lower atmosphere, which is known to generate adverse daytime dispersion conditions over snowfree ground. This situation results since the relatively low surface sensible heat fluxes during the winter are ineffective in forcing a deep enough daytime $\mathrm{ABL}$, due to the stable thermal stratification characteristics associated with a polar or Arctic high pressure system. Based on the evaluations in the present study it is suggested that in situations when the ground is snow covered, the additional suppression of the sensible heat flux over snow leads to an enhanced suppression of the daytime development of the ABL. Thus, considerable deterioration in pollutant dispersion conditions are likely to occur under such situations.

(4) It is worth noting that, following Johnson et al. (1984), Cramer (1988), Segal et al. (1991a, b), local thermally-induced circulations may be generated along the boundary between snow and bare soil (analogous to sea/lake breezes). In the study reported in those contributions, a possible suppression of the daytime thermally induced upslope flow was also suggested. Thus, in some locations and situations, an additional impact upon dispersion may result from snow-related induced or suppressed thermal circulations.

Finally, results presented here indicate the need for additional studies on the impact of snow cover on pollutant dispersion, leading to quantitative guidelines to be used for evaluating pollutant dispersion over snow cover at mid-latitudes.

Acknowledgements-The study was supported by EPRI contract \# RP-1630-53, NSF grants \# ATM-8616662 and \# ATM 8915265. The SSBLIM project was carried out using the NCAR King Air Aircraft operated by the NCAR Aviation Division. The BAO meteorological data were obtained from NOAA/ERL at Boulder. GOES satellite imagery and other real time meteorological data in support of the SSBLIM were obtained by the PROFS-SERS at the Cooperative Institute for Research in the Atmosphere, and at the NOAA/NESDIS/RAMM Branch Data Utilization Center (VDUC), CSU. We would like to thank G. Summer and the NCAR RAF staff for the management of the aircraft measurements, and to $D$. Wolfe for his help relating to access to the BAO data. G. Kallos, J. Purdom, J. Weaver, Z. Ye and R. Zehr provided useful help during the SSBLIM operational phase. The authors would also like to thank D. McDonald and $B$. Critchfield for typing the manuscript.

\section{REFERENCES}

Aguado E. (1985) Radiation balance of melting snow covers at an open site in the central Sierra Nevada, California. Wat. Resour. Res. 21, 1649-1654.

Bluestein H. B. (1982) A wintertime mesoscale cold front in the southern plains. Bull. Amer. met. Soc. 63, 178-185.

Brutsaert W. (1982) Evaporation into the Atmosphere. D Reidel, New York.

Chamberlain A. C. (1983) Roughness length of sea, sand and snow. Boundary-Layer Met. 25, 405-409.

Cramer J. (1988) Observational evaluation of snow cover effects on the generation and modification of mesoscale circulations. Paper No. 439, Department of Atmospheric Science, Colorado State University, Fort Collins, CO.

Daugharty D. A. and Dickison R. B. B. (1982) Snow cover distribution in forested and deforested landscapes in New Brunswick, Canada. Proc. Eastern Snow Conf., pp. 10-19.

Dewey K. F. (1977) Daily maximum and minimum temperature forecasts and the influence of snow cover. Mon. Weath. Rev. 105, 1594-1597.

Dickinson R. E., Henderson-Sellers A., Kennedy P. J. and Wilson M. F. (1986) Biosphere atmosphere transfer scheme (BATS) for NCAR community climate model. NCAR Technical Note 275, Boulder, CO.

Geiger R. (1965) The Climate Near Surface. Harvard University Press, Harvard.

Golder D. (1972) Relations among stability parameters in the surface layer. Boundary-Layer Met. 3, 47-58.

Granger R. J. and Male D. H. (1978) Melting of prairie snowpack. J. appl. Met. 17, 1833-1842.

Gray D. M. and Male D. H. (1981) Handbook of Snow. Pergamon Press, Oxford.

Haltiner G. J. and Martin F. L. (1957) Dynamical and Physical Meteorology. McGraw-Hill, New York.

Hicks B. B. (1981) An analysis of Wangara micrometeorology: surface stress, sensible heat, evaporation, and dewfall. NOAA Technical Memorandum ERL ARL-104.

Hicks B. B. and Martin H. C. (1972) Atmospheric turbulent fluxes over snow. Boundary-Layer Met. 2, 496-502.

Johnson R. H., Young G. S., Toth J. J. and Zehr R. M. (1984) Mesoscale weather effects on variable snow-cover over Northeast Colorado. Mon. Weath. Rev. 112, 1141-1152.

Mahrer Y. and Segal M. (1979) Simulation of advective Sharav conditions over Israel. Israel J. earth Sci. 28, 103-106.

Mellor M. (1977) Engineering properties of snow. J. Glaciol. 19, 15-66.

Monteith J. L. (1981) Evaporation and surface temperature. Q. Jl R. met. Soc. 107, 1-27.

Penman H. L. (1956) Evaporation: an introductory survey. Neth. J. agr. Sci. 4, 9-29.

Segal M., Cramer J. H., Pielke R. A., Garratt J. R. and Hildebrand P. (1991a) Observational evaluation of the snow breeze. Mon. Weath. Rev. 119, 412-424.

Segal M., Garratt J. R., Kallos G. and Pielke R. A. (1989) On the impact of wet soil temperature and canopy temperature on the daytime development of the boundary layer. J. atmos. Sci. 46, 3673-3684.

Segal M., Garratt J. R., Pielke R. A. and Ye Z. (1991b) Scaling and numerical model evaluations of snow-cover on the generation and modification of daytime mesoscale circulations. J. atmos. Sci. (in press).

Segal M., Jia X., Ye Z. and Pielke R. A. (1990) On the effect of daytime surface evaporation on pollution dispersion. Atmospheric Environment 24A, 1801-1811.

Slade D. H. (1968) Atmospheric dispersion over Chesapeake Bay. Mon. Weath. Rev. 90, 217-224. 
Swinbank W. C. (1963) Long-wave radiation from clear skies. Q. Jl R. met. Soc. 89, 339-348.

Tennekes H. (1973) A model for the dynamics of the inversion above a convective boundary layer. J. atmos. Sci. 30, 558-567.

Turner D. B. (1964) A diffusion stability model for an urban area. J. appl. Met. 3, 83-91.
Uthe E. E., Nielson N. B. and Jimison W. L. (1980) Airborne lidar plume and haze (ALPHA-1). Bull. Amer. met. Soc. 61, 1035-1043.

Wiscombe W. J. and Warren S. G. (1980) A model for the spectral albedo of snow-I. Pure snow. J. atmos. Sci. 37, 2712-2733. 